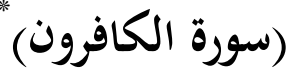

\section{قراءة بلاغية}

\section{أسماء سعود الخطاب}

قسم اللغة العربية، كلية الآداب، جامعة الموصل، العراق.

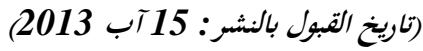

الملخص:

ونحن إذ نحلل السورة على وفق قراءة بلاغية خاصة فإننا ننظر إلى الظواهر البلاغية في نسيج السورة بوصفها لوحة فنية

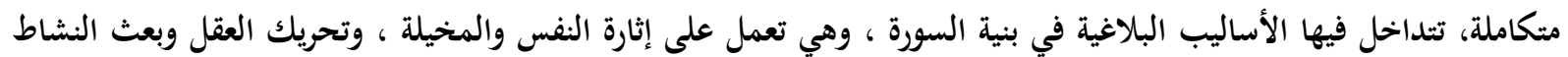

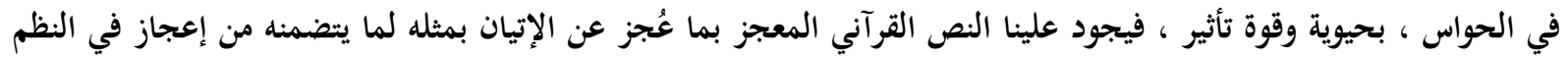

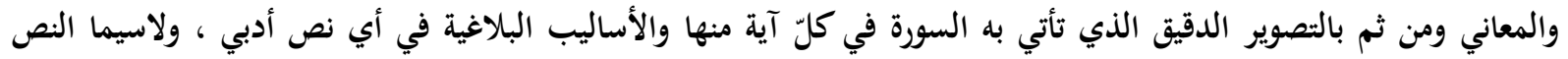

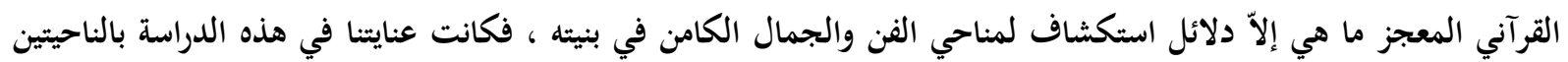
البلاغية والصوتية واضحة ـ ففيما يتصل بجانب المعنى حاولنا أن نبيّن الترابط المعنوي بين آيات السورة في ضوء أساليبها البلاغية ، ومن أهم مظاهر ذلك الترابط هو الوصول إلى النتيجة الحتمية التي يدور حولها النص بضرورة حسم الموقف (الآن) بين الرسول

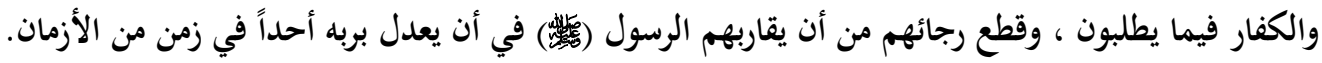

الحال والاستقبال وأن دين الإسلام لا يخالط شيئاً من دين

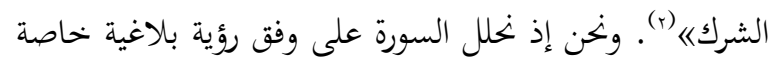
فإننا ننظر إلى الظواهر البلاغية في نسيج السورة بوصفها لوحة لونة

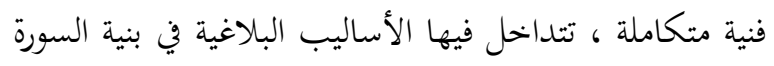

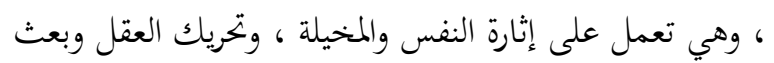

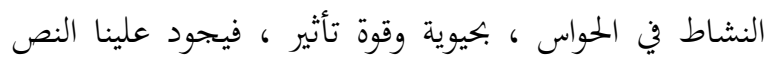

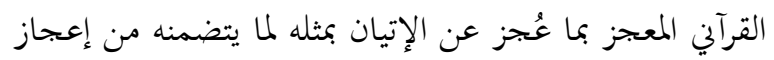
في النظم والمعاني ومن ثم بالتصوير الدقيق الذي تأتي به السورة

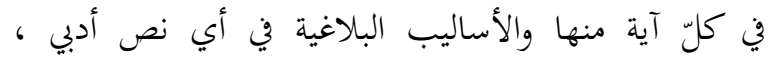

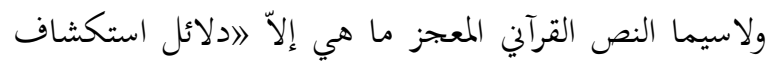

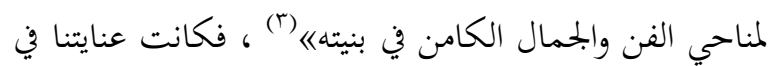
هذه الدراسة بالناحيتين البلاغية والصوتية واضحة ـ ف فنيما

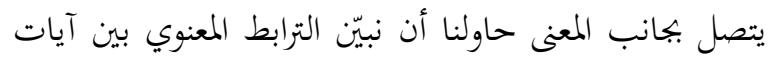

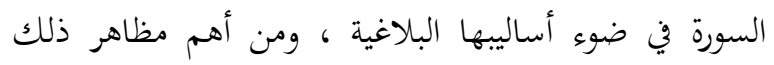

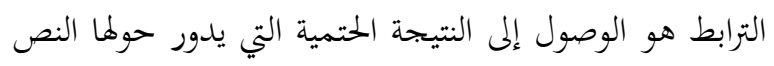
بضرورة حسم الموقف (الآن) بين الرسول والكفار فيما

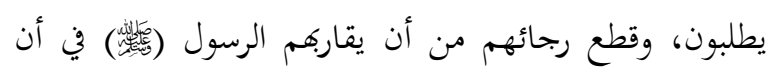

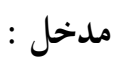
يتناول البحث (سورة الكافرون) وهي سورة مكية باتفاق وعدد آياما ست ، وروي في سبب نزولها فيما رواه الواحدي: أن رسول الله (ئس

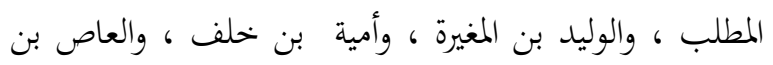
وائل ، وكانوا ذوي مكانة في قومهم فقالوا : يا محمد هلم

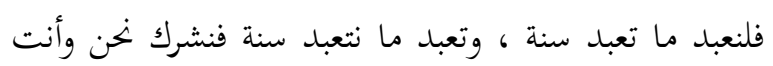

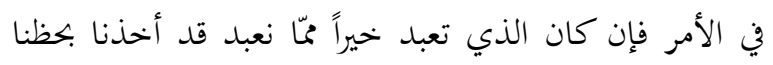

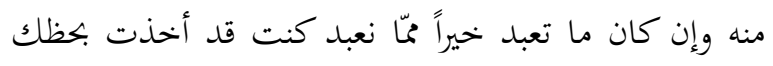

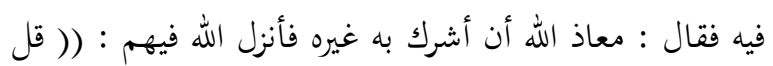

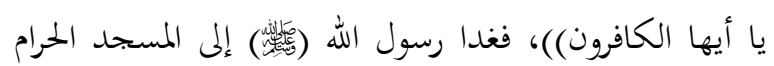
وفيه الملأ من قريش فقرأها عليهم فيئسوا فيه عند ذلك (1) .

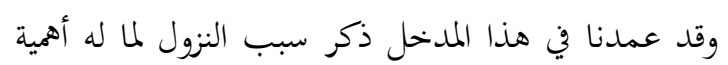
كبرى في إضاءة الظواهر الأسلوبية والبلاغية التي شكلت

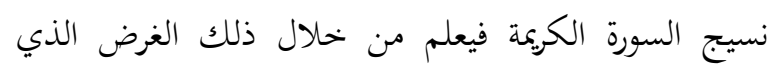
اشتملت عليه وهو التأييس قريش في أن يوافقهم الرسول

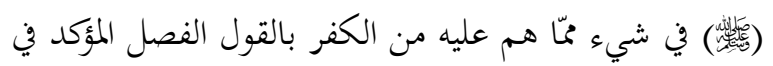


يعدل بربه أحداً في زمن من الأزمان ـ وفيما يتصل بالجانب ع ـ تقديم المسند على المسند إليه في (لكم دينكم

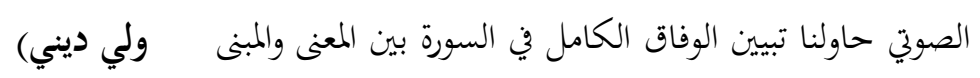

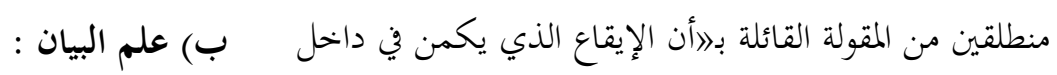

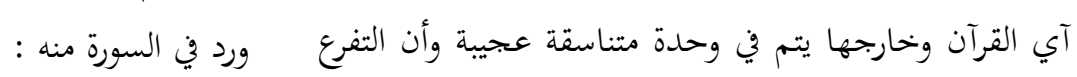

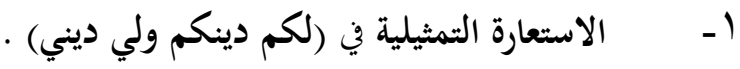

$$
\text { ج) علم البديع : }
$$

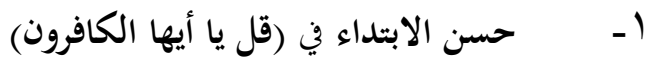

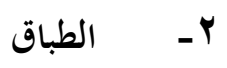

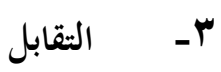

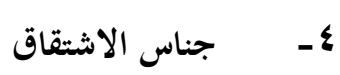

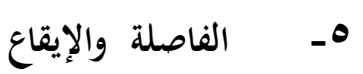

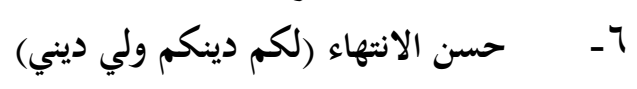

وقد تواشجت هذه الأساليب البلاغية جميعاً في نسيج

السورة على نحو متناغم في توصيل مقاصد السورة وأهدافها

إلى المتلقي بطريقة موحية مؤثرة.

$$
\text { القسم الأول : المتلفي بطريقة }
$$

إذا كان للعنوان أثر في الإفضاء ببعض ما يبوح به النص

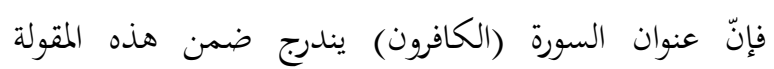
النقدية؛ وذلك من خحلال البث الدلالي الذي يوحي به بهد العنوان، فقد جاءت لفظة الكفر بصيغة اسم الفاعل بحموعاً

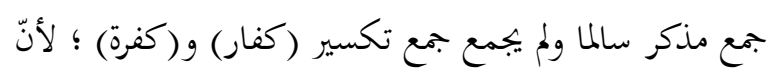

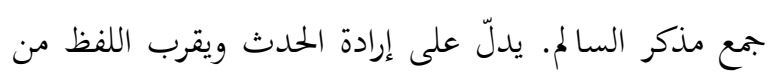

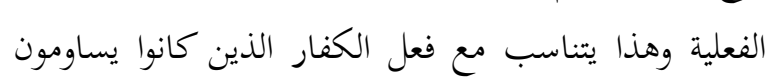

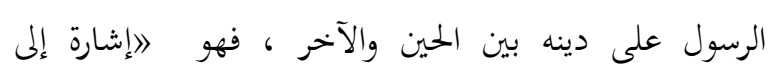

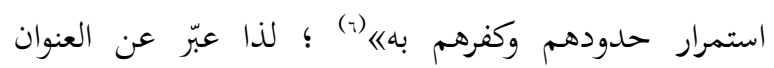

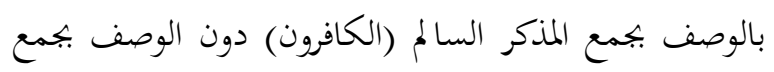
التكسير ليفضي ذلك العنوان إلى مضمون السورة.

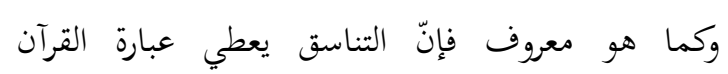

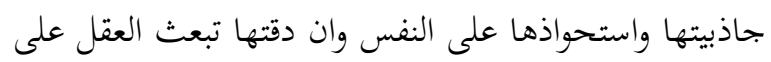
ممارسة في التدقيق ونخن قد نلمس هذا التناسق في إيقاعه ؛

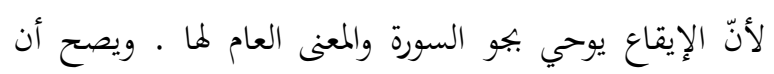

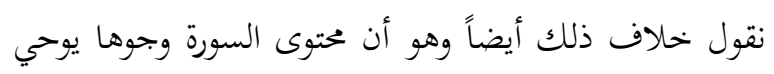

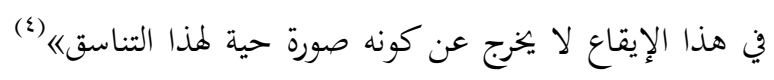
فيطالعنا أنواع من الإيقاع في هذه السورة : . الإيقاع بالنكرار

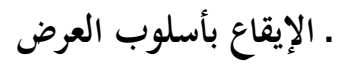

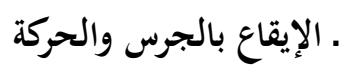

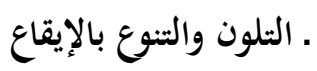
فضلاً عن إيقاع الفكرة ، لتصب جميعاً في معين واحد هو لإلوعاع التناسق في النظم البلاغي المعجز انطلاقاً من اللفظة القرآنية

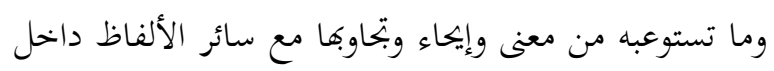

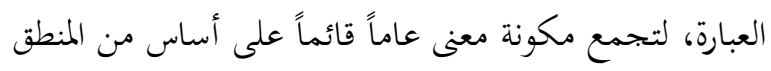

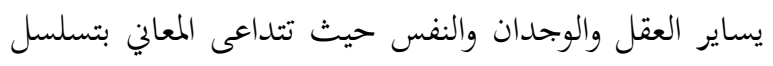
منطقي ويحصل هذا التداعي عن التروي في تحليل النص وتأمله (م). وسنعمد قبل تحليل السورة إلى إيراد نصها الكريم أولاً ،

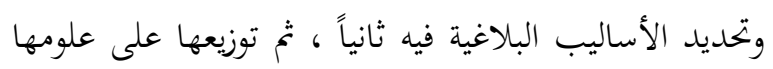

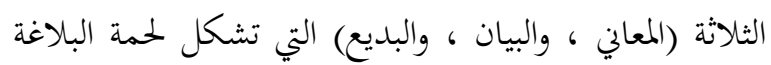

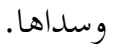
النص :

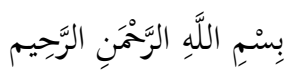

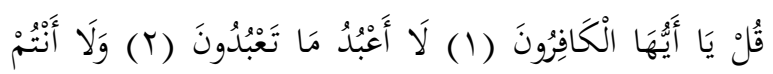

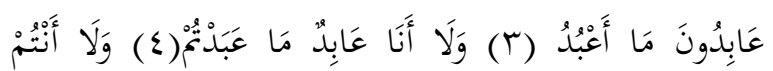

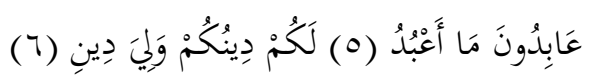

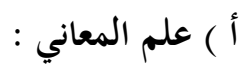

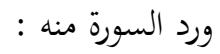
ا - الأسلوب الإنشائي : الأمر (قل) + (النداء) : (يا

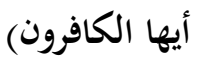

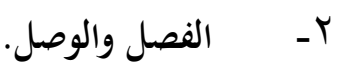
r- ـ الاعتراض في (ولا أنا عابد ماعبدتم). 
اي في الحالتين الثابتة والمتجددة في جميع الأزمنة وهذا غاية الكمال (1.) ثم ينتقل السياق إلى الشرط الثاني وهو مختص بقريش فبعد

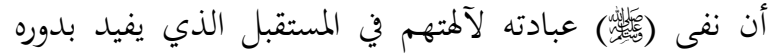
نفي عبادتا في الحال بدلالة فحوى الخطاب ، جاء في مثاله نفي عبادةم لله بنفي اسم الفاعل الذي هو حقيقة في الحال

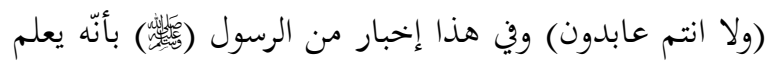

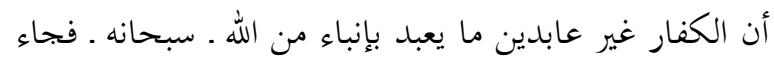

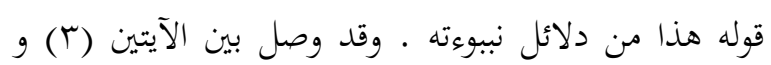
(§) لمناسبة بينهما هي نفي أن يعبد الكفار الله . -سبحانه -.

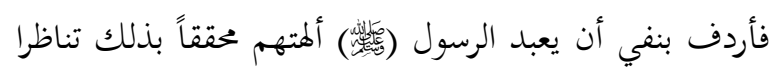

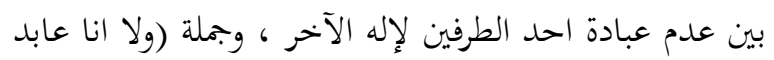
ما عبدتم) معترضة بين التأكيد (ولا انتم عابدون ما اعبد)

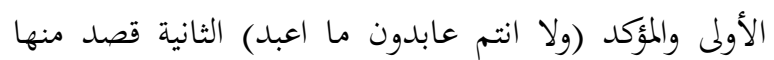

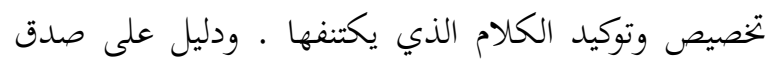

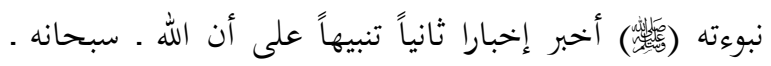

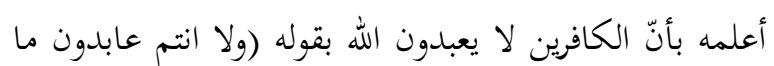

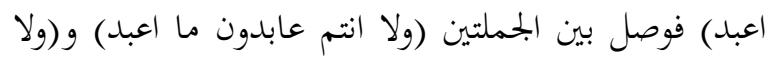

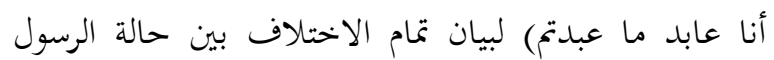

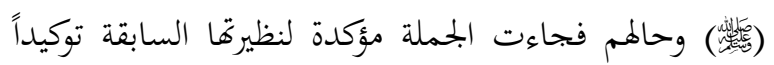

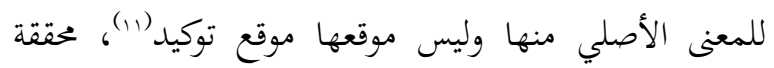

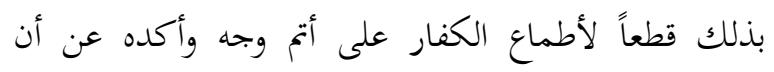

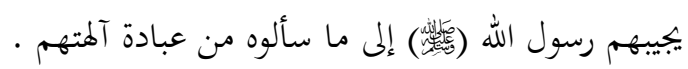

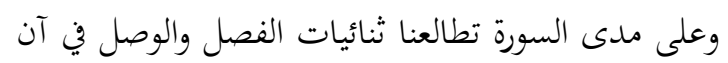
واحد، فالفصل المتحقق بين الآية الأولى والثانية ، والآية

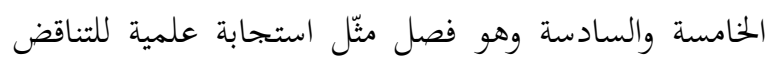

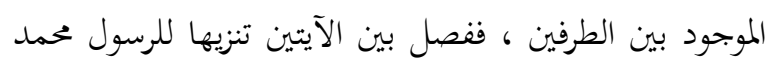
(الحّف

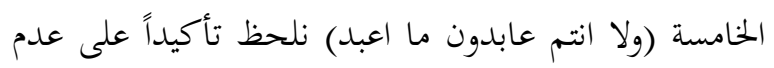

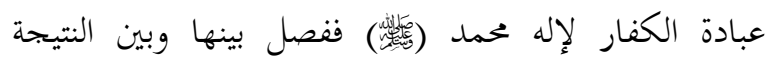
الحتمية لوجود بون شاسع بين الكفار والرسول ، فهم لهم شركهم وهو له توحيده أمّا الوصل فمتحقق بين الآيات الثانية والثالثة والرابعة والخامسة لما وقع بينها من مناسبة في المعنى.
بتنوع الإيقاع أيضاً وإذا ما أجرينا موازنة بين آي الصدارة

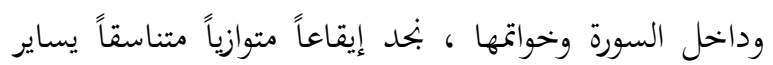
نوع إيقاع جو السورة. وبما أن السورة تتخصص على فكرة أساسية هي المفاصلة

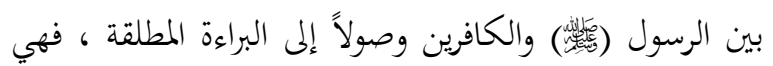

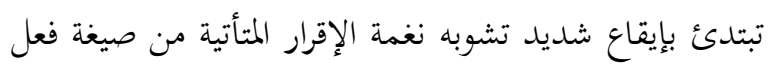

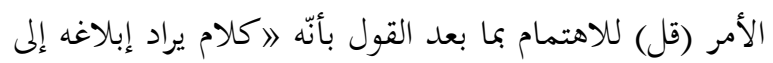

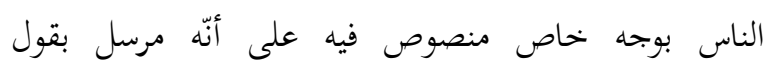

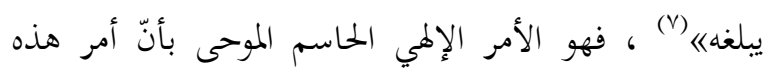

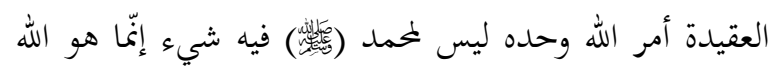
الآمر الذي لا مرد لأمره. فضلاً عن النداء بأداة البعد المؤكدة إلهاء

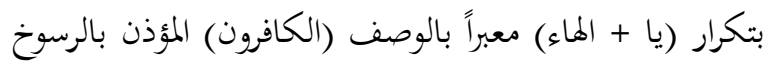

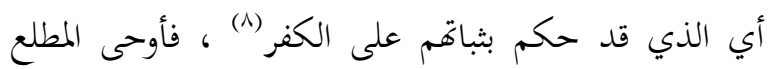

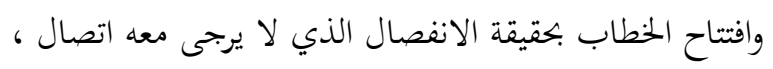

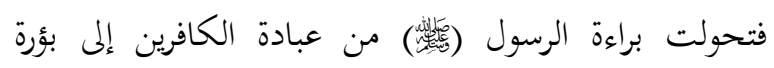
تتدفق منها الآيات على شكل ثنائيات زمنية بين الحال

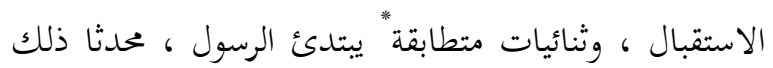
لحله بتحاوبا بين المنطوق والمدلول.

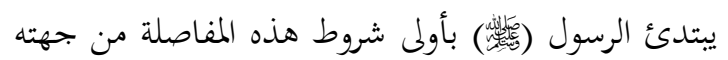

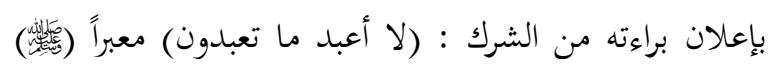

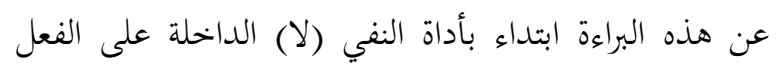

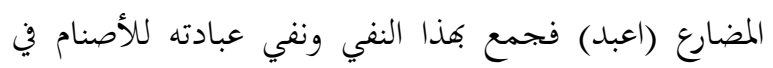

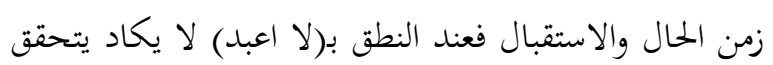
هذا الفعل حتى بمعنى زمن فيصير مستقبلاً فجاء التعبير بـ(لا)

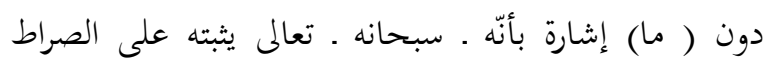

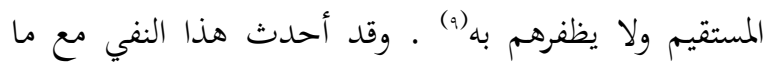
أردفه من عبارة (ما تعبدون) مباينة دلالية قامت على التضاد

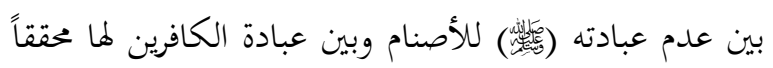

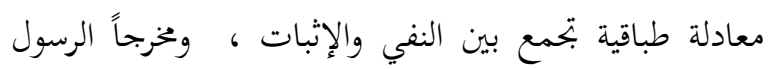

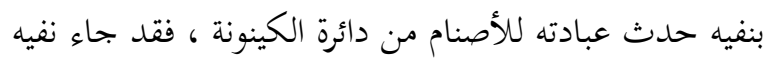
بالصيغتين الفعلية والاسمية (لا اعبد ما تعبدون) و(لا انا عابد ما عبدتم) · وبالفعلين المضارع والماضي (تعبدون) و و(عبدتي) 
إشباع العقل وإرضاء النفس ونود في هذا القسم أن نقصر الحديث عن ظاهرة التلاؤم الصوتي التي تحلت في العلم الثالث من علوم البلاغة ـ علم البديع ـ الذي جاءت أنواعه في السورة

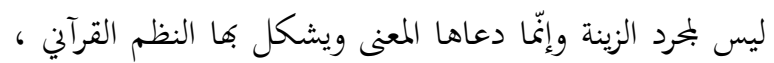

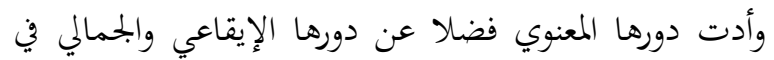
مكانها في النص. ومن خلال تواشج العلوم الثلاثة ظهر النص كبنية واحدة كلّ عنصر بشكل بلاغي فيه مثل بنية أو خلية تتشابك وتتعاضد مع بقية البنى في تكوين الكيان العضوي للنص ولعلنا لا نخطئ إن رددنا ـ مع من يقول ـ سحر القرآن في

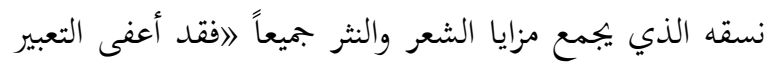

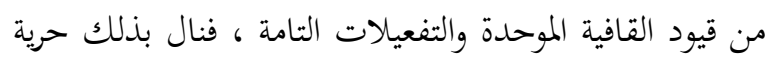
التعبير الكاملة عن جميع أغراضه العامة واخذ في الوقت ذاته من خصائص الشعر الموسيقي الداخلية ، والفواصل المتقاربة في الوزن التي تغني عن التفاعيل والتقفية التي تغني عن القوافيه(1)، وان هذه الموسيقى الداخلية لتنبعث في القرآن حتى في اللفظة المفردة في كل آية من آياته فتكاد تستقل

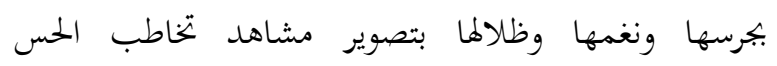
والوجدان وتصل إلى النفس من منافذ شتى بالتخييل والإيقاع.

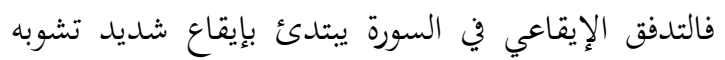

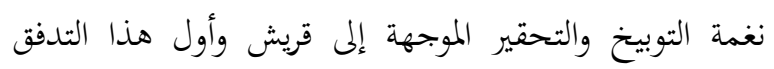

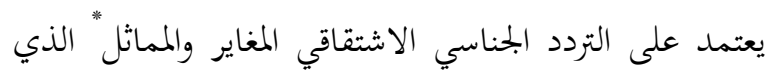

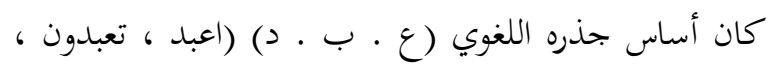

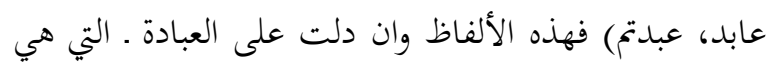

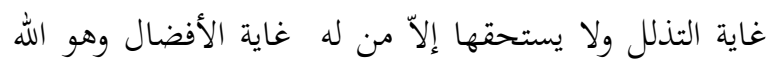
تعالى(r) ، فضلا عن كوغا الأصل الأصيل في العقائد لا يتغير فيها الرأي ؛ لأنّ تشريعات العبادة لله ، ووححدانية الله وعدم الهام

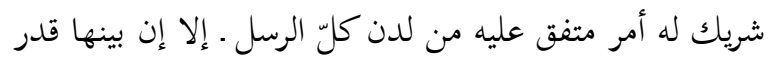

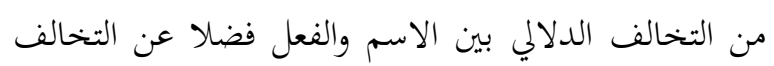
الزمني بين الصيغ وتواشجها السياقي مع بقية النظم الجملي.

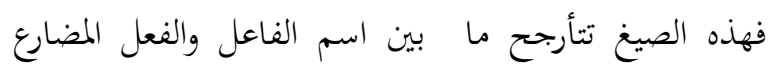

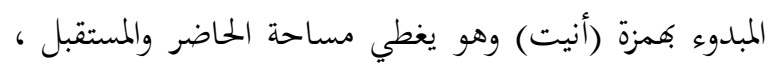

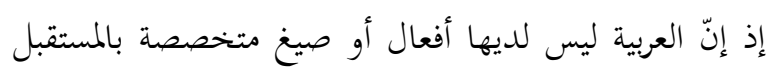

وفي خضم المقارنة نتلمس البعد الاستعاري في حسن

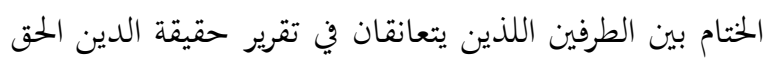
ودين التوحيد بقوله (لكم دينكم ولي دين) حيث وضع بين

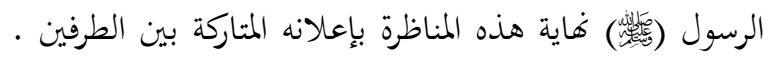
ومن خلال تقديم المسند على المسند إليه ودلالة (اللام) لشبه

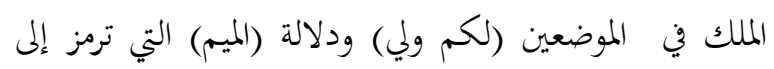

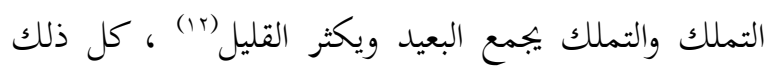
حقق الاختصاص في دين كل طرف وذلك بأن الكافرين لهم دينهم الذي هو الإشراك مقصور على الحصول لهم لاين

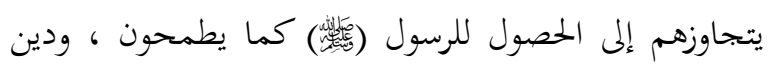

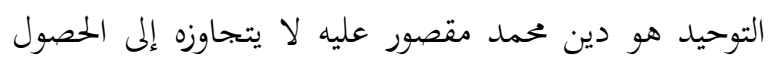
dir) وقد جرت عادة العرب بان يتمثلوا بهذه الآية عند المتاركة،

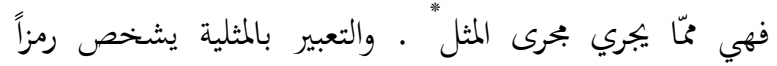
واضحاً، ومثلا في التعبير عن مواقف نلمح فيكائ فيها المشابهة

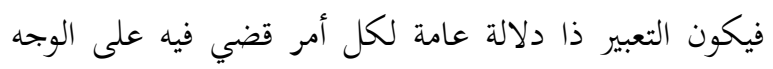

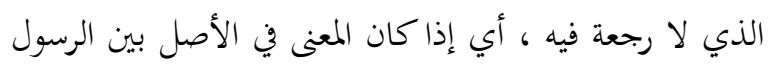

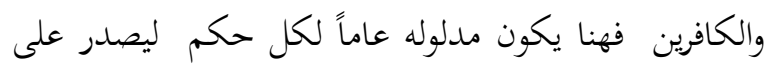

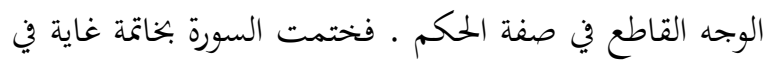

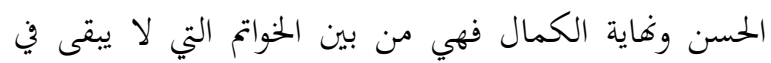
النفوس بعدها تطلع ولا توق إلى ما يقال (s؛ ).

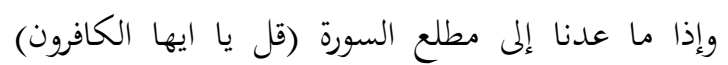
وجدنا أنّه يؤذن بخاتمتها (لكم دينكم ولي دين) وما بين هذا لها

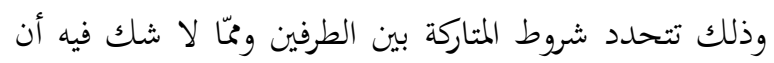
آخر السورة الذي هو اختصاص كلّ بدينه هو أولها الذي أفاد

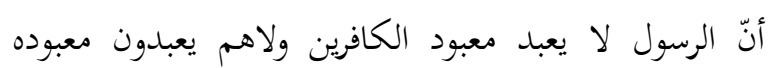

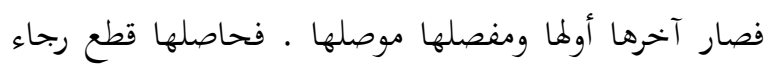

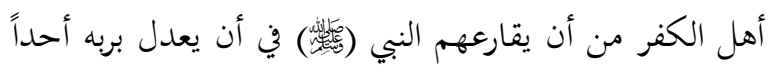
في زمن من الأزمان (10).

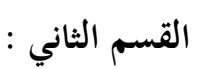
فيما سبق ابتهت نظرتنا فيه غالباً إلى المعنى من زاوية

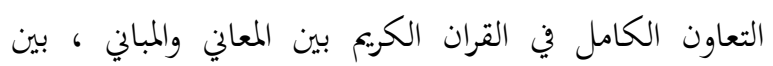


أما التقابل بين النفي /الإثبات فيمكن توضيحه بالشكل

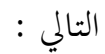

\begin{tabular}{|c|c|}
\hline الكافرون & الرسول \\
\hline ما تعبدون / إثبات عبادة & لا اعبد / نفي عبادة أصنام \\
\hline الأصنام لهم & عنه \\
\hline ولا انتم عابدون / نفي & ما اعبد / إثبات \\
\hline ما عبدتم / إثبات & ولا أنا عابد / نفي \\
\hline
\end{tabular}

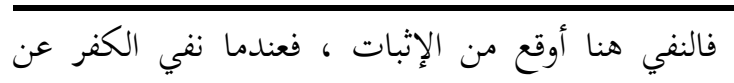

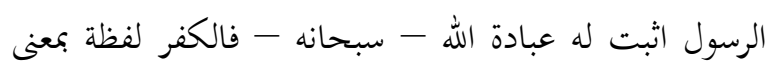

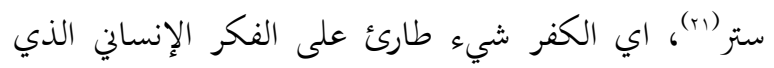
خلق بطبيعته مؤمن ، فوجود الإيمان بالله بالفطرة وبالبرهان

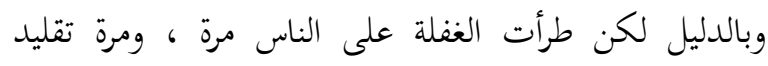

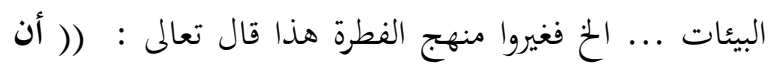
تقولوا يوم القيامة إنا كنا عن هذا غافلين أو تقولوا إنما

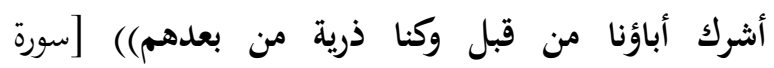
الأعراف] ، إذن فعندما نفي الكفر عن الرسول اثبت له له ضمنيا فطرية الإيمان فجاء النفي بمنزلة توكيد للاثبات.

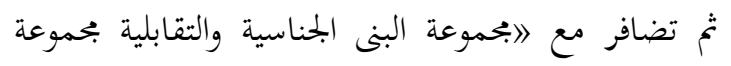
أصوات مهيمنة على جو السورة بعامة منها صوت (العين)

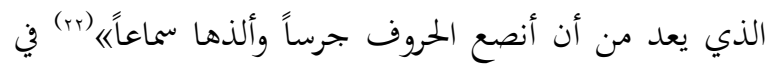

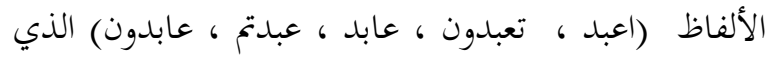

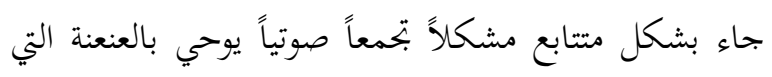

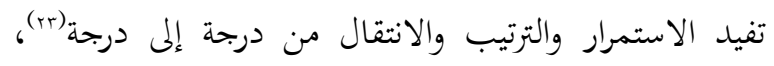

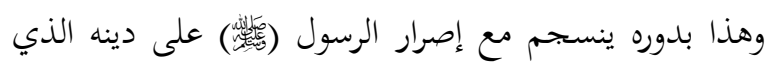

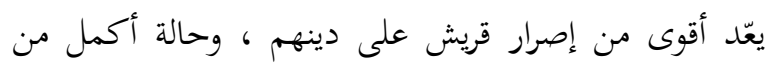

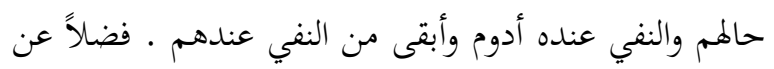

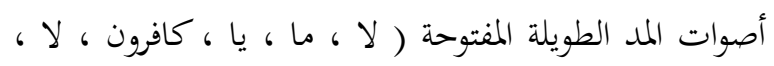

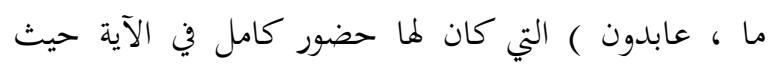
عملت على تشكيل أصوات متجانسة تؤلف المحور الأساسي

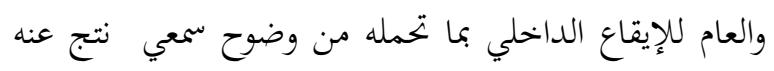
القدرة على استيعاب مشاعر الغيرة والغضب والمرارة بتحاه

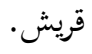

فحسب إنّما المستقبل فيدرج من ضمن صيغ الحال ،و المضارع

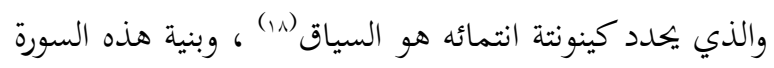
تقوم على : العبادة والزمن من خلال خطاب ثنائي بين

\begin{tabular}{|c|c|}
\hline الكافرون & الرسول \\
\hline ولا انتم عابدون ما اعبد & لا اعبد ما تعبدون \\
\hline (الحال) & (الحال) \\
\hline ولا انتم عابدون ما اعبد & ولا أنا عابد ما عبدتم \\
\hline (المستقبل) & (المستقبل) \\
\hline
\end{tabular}

فنلاحظ التزام الصيغة التي تخص الكافرين شكلا واحداً و

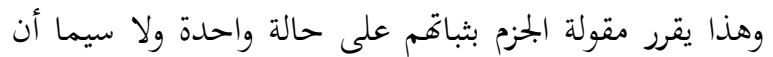
عنوان السورة ( الكافرون ) يدعو إلى ذلك (19).

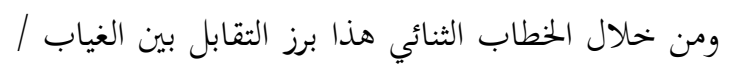

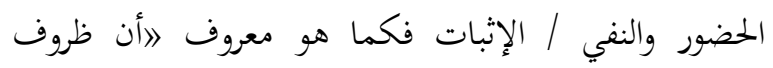
البشر متغيرة و وتغيير ظروفهم لا يملكون فيها شيئا ، أمور تجري عليهم و وتفكيرهم نقص لأفم لا يعلمون ما يستقبل

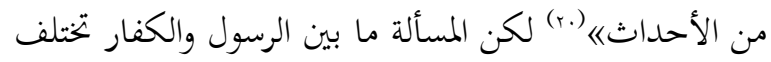

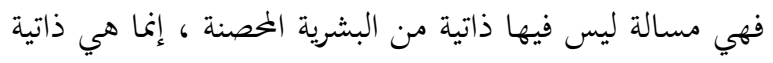

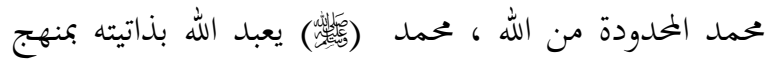
من الله فحدث هنا (غياب للذاتية) فالحق ـ سبحانه ـ. هو

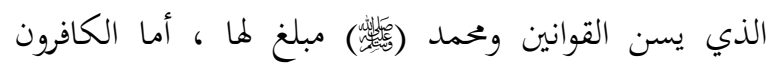

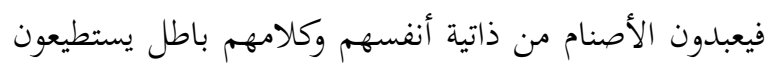

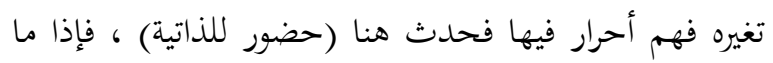

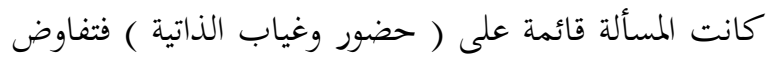
الكافرون مع الرسول تفاوض أحمق وعقيم لأفم يتفاوضون في

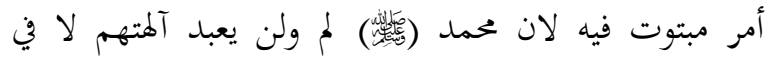
السابق ولا في الحال أو المستقبل ، فالظرف في مسألة العقائد

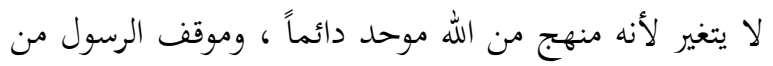
عبادة الكافرين هو موقف دائمي. 
شحن المتلقي ضد واقع دأبت السورة من بدايتها حتى النهاية على التنديد به لفساده ، ومع هذا التصاعد النغمي الذي دئي عمل على استجلاء وتعميق صورة الصراع القائمة بين الرسول والكافرين على مدى السورة الكريمة، يصل الإيقاع إلى ذروته في آية الختام (لكم دينكم ولي دين) ، فالإيقاع الذي يحدثن الإيقاع إلى درونه

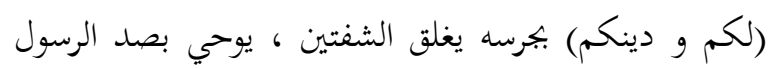

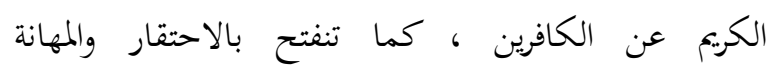
واللامبالاة، فضلا عن نغمتها المشوبة بالزبحرة ، فتنعكس هذه النغمة على النفس فتهزها هزاً.

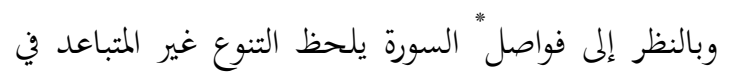

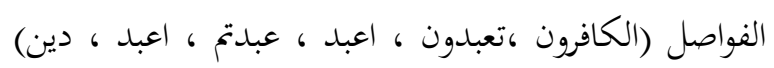
حيث الروي المتماثل في ثلاث فواصل بحرف الروي (النون)،

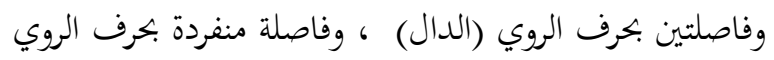

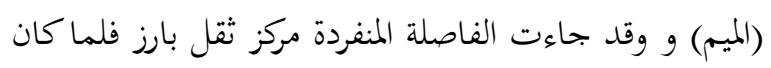

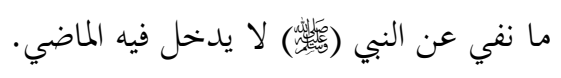
وإذا ما نظرنا إلى السورة على أها مقسمة على ثلاثلة أقسام

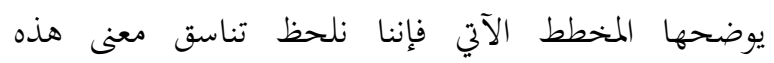
التقسيمات مع الفاصلة مع المقطع الصوتي وروي الفاصلة(rs).
كما تلمس من الإيقاع ضربات نفسية حادة تدركها نفس

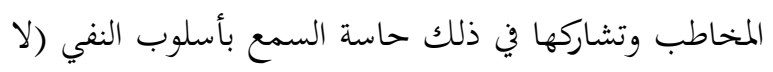

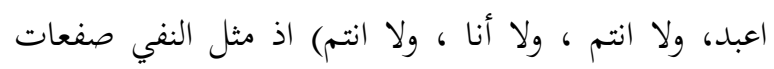

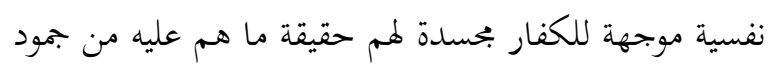
في التفكير وعدم القدرة على النظر في عقيدة التوحيد التي كان يدعوهم إليها الرسول (لفئس

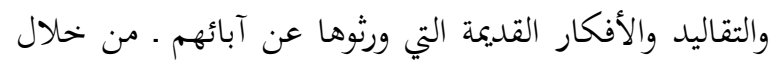

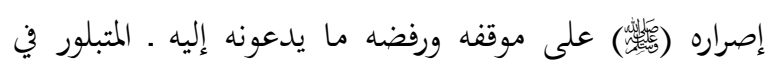

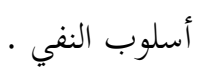
وإذا ما تأملنا عملية الالتفات من صيغة المخاطب (الكافرون) إلى المتكلم (الرسول) وانسجامها مع الانتقالات

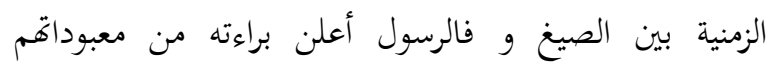

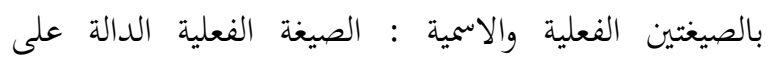
الحدوث والصيغة الاسمية الدالة على الثبات لتعلن براءته فيها على كل حالة ثم انه استغرق الزمن الماضي والحال والاستقبال

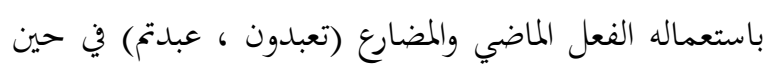
نفاه عنهم بالصيغة الاسمية فقط ، إذن هناك تناسب حركي

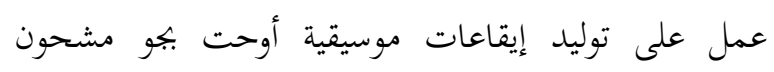

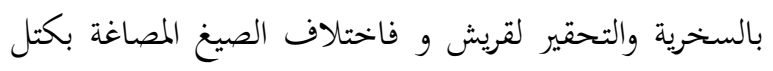

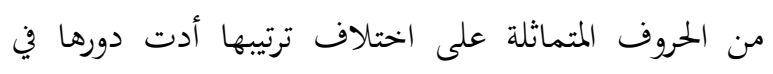

\begin{tabular}{|c|c|c|c|}
\hline المعنى & الصوت & المقطع الصوتي & الآية \\
\hline إعلام الكافرين أنه(ص) لا يعبد ما يعبدون. & 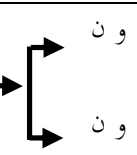 & $\begin{array}{l}\text { صحて } \\
\text { صحて }\end{array}$ & 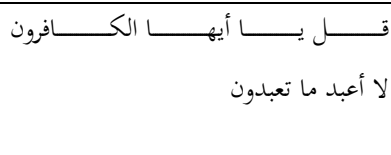 \\
\hline الفاصلة التوكيد على مـا سبق يدخل اليأس إلى قلوب الكفار وظهور & $\begin{array}{c}{ }^{2} \\
\\
\\
\end{array}$ & 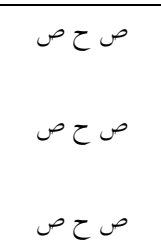 & 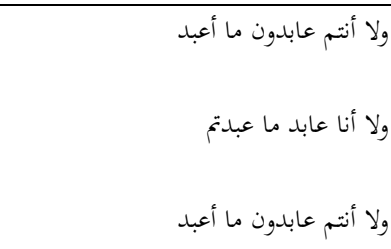 \\
\hline 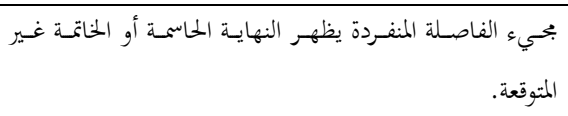 & ن ن & ص حصص & لكم دينكم ولي دين \\
\hline
\end{tabular}


(Ir)

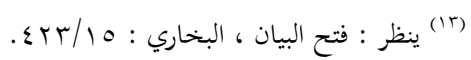

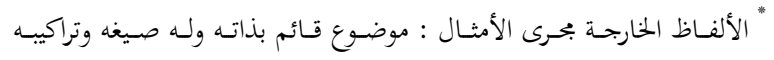

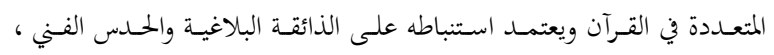

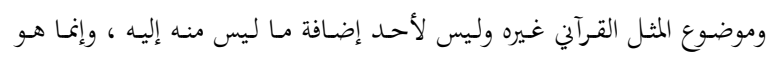

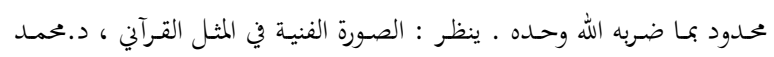
حسن علي الصغير / . 11. أما المثل القرآي : لا حالة سابقة يقاس عليها ولا نظائر يشار إليها وإنما أنزلت لإلت

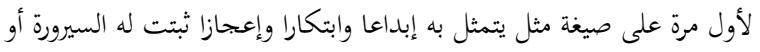

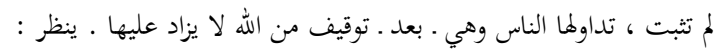

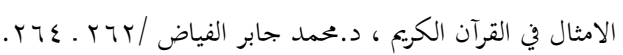

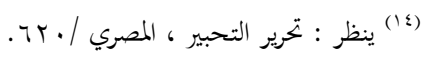

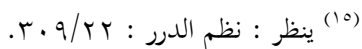

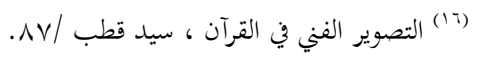

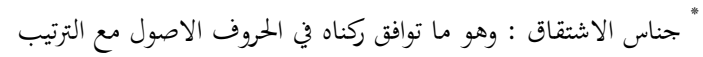

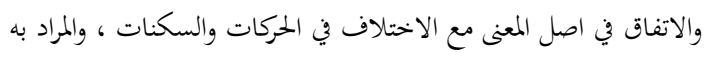

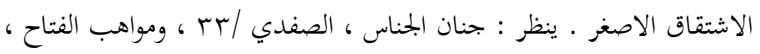

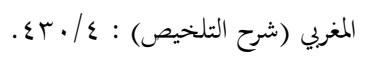

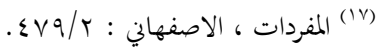

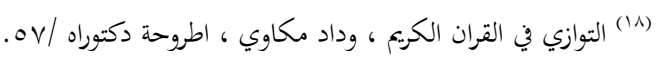

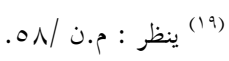

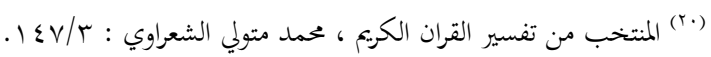
ينظر (Tr)

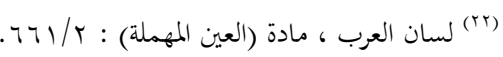
(Tr) " هناك ثلاثة أنواع من الفواصل القرآنية : الأولى : الفواصل المتماثلة : وهي التي

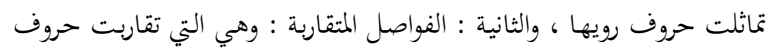
رويها كثقارب الميم من النون مثثلا ، والثالثة : الفواصل المنفردة : وهي نادرة وهي التي لم تتماثل حروف رويها ولم تتقارب وهذه الفواصل المنفردة لا تتجاوز

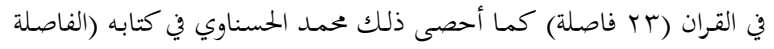
في القران (كT)

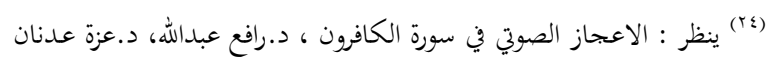

$$
\begin{aligned}
& \text { s/ ينظر : (ro) }
\end{aligned}
$$

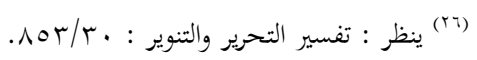

$$
\begin{aligned}
& \text { ينظر : نظم الدرر : (rV) }
\end{aligned}
$$

ثبت المصادر والمراجع

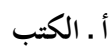

الاعجـاز الفني في القرآن ، عمـر السـلامي ، مؤسسـات عبـدالكريم عبـدالله ،

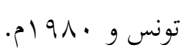

فصسورة المفاصـلة في العبـادة بـين الكافرين والرسـول (صـلى الله عليه وسلم) من خلال تناوب أصوات الفاصلة في الآيات التي تتحدث عن العبادة، فالتعاقب بينها واضح، وكأنه يمثل العرض تر الذي يقتضي تقسيم العبادة بين الله وبين الشركاء على نوبات زمنية، وهذه تقتضي التكرار لدى التطبيق(ro().

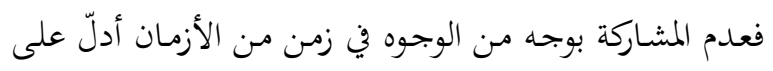
البراءة واقعد في دوام الاستهانة بالفعل الماضي في قوله (عبدتم) للدلالة على رسوخهم في عبادة الأصنام لأزمان قضت ، وفيه

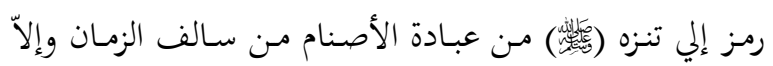
قال: ( ولا انا عابد مـاكنا نعبد ) فقد كان الكافرون يعدون

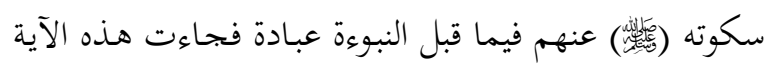
بفاصـلة منفــدة تؤذن بإثـارة اليقظـة وشـد الانتبـاه إلى فحـوى الآيـة(َr) . كـل مـا تقـدم مـن طاقـات صـوتية كـان لهـا الأثـر العميق في توضيح دلالة النص التي تدور حول ضرورة حسم الموقـف (الان) بــن الرسـول والكفــار فيمـا يطلبـون ، وقطع

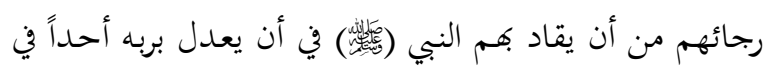

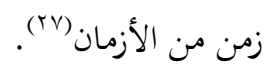

* عنونـت هـذه السـورة في المصـاحف التي بأيسـينا قـديمها وحسـيثها بـ(سـورة الكافرون) باضافة (سورة) إلى (الكافرون) وبثبوت (الواو) للرفع في (الكافرون)

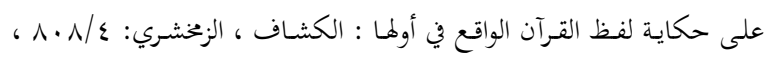

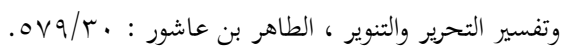

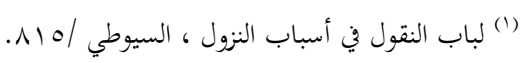

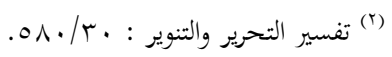

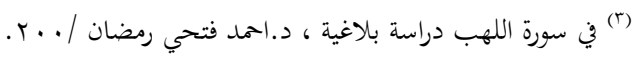

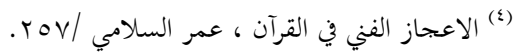

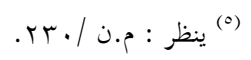

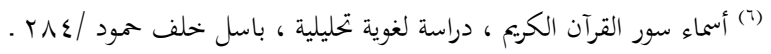

$.4 \wedge 0$

$$
\text { (V) }
$$

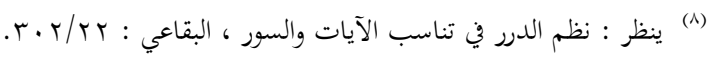

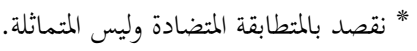
(9)

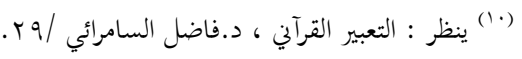

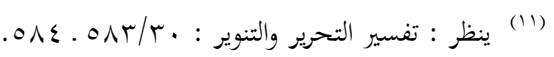


لباب النقول في اسباب النزول ، السيوطي ، في هـامش تفسير الجلالين ، دار

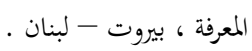

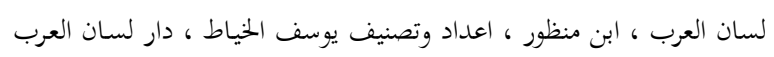

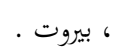

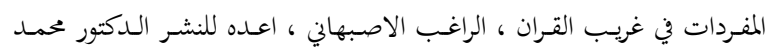

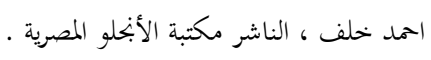

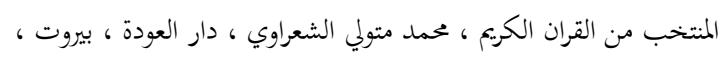

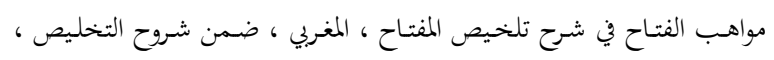

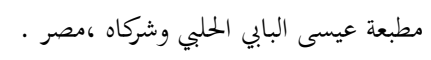

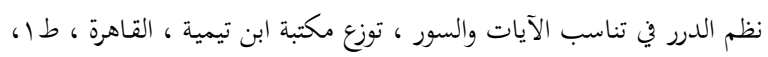
. $1979-81 \% 19$

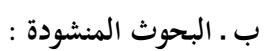

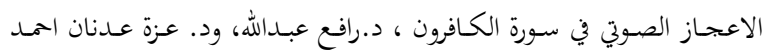

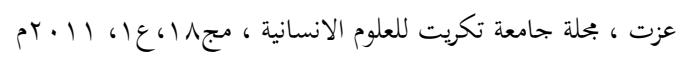

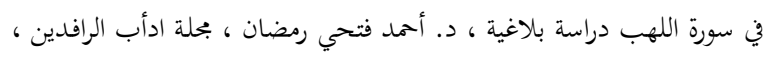

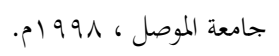

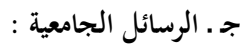

اسماء سور القران الكريم ، دراسة لغوية تحليلية ، باسل خلف حماتل الجمود ، رسالة

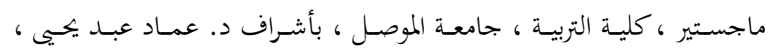

التوازي في القران الكريم ،وداد مكاوي حمود الشمري ، اطروحة دكتوراه ، كلية

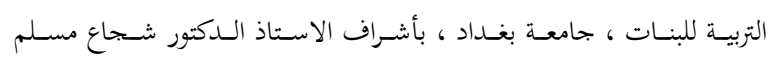

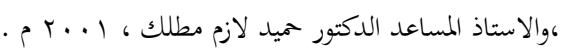

الأمثـال في القـرآن الكـريم ، د. محمــــــــابر الفيـاض ، بغــاد و دار الشـؤون

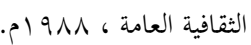

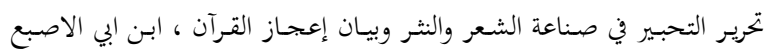

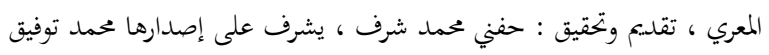

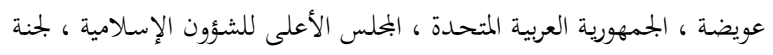

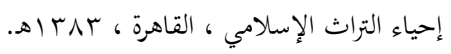

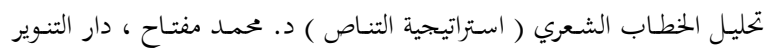

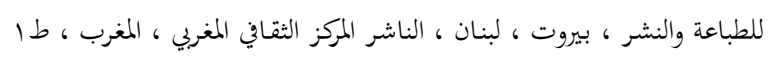
.01910 ، التصوير الفني في القران ، سيد قطب ، دار الشروق و القاهرة ، ( د. ت ) .

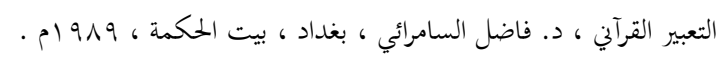

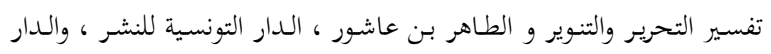

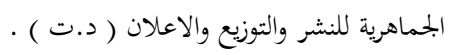

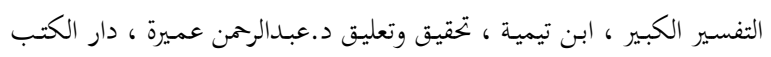

$$
\text { العلمية ، بيروت و لبنان. }
$$

جنان الجناس في علم البديع ، الصفدي ، طبع في مطبعة الجوائب ، قسطنطينية . 1) 996 الصـورة الفنيـة في المثل القـرآني ، د. محمـد حسـين علي الصغير ، دار الرشيد

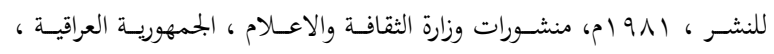

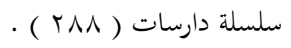

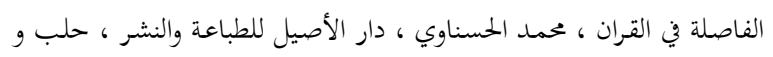

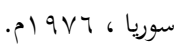

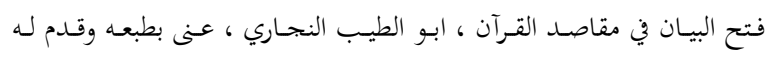

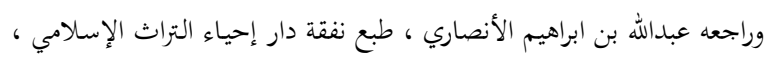

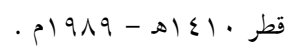
الكشاف عن حقائق الثنزيل وعيون الأقاويل في وجوه التأويل ، الزخشري ، دار

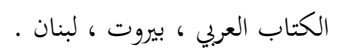

